\title{
In vivo corneal confocal microscopy and optical coherence tomography on eyes of participants with type 2 diabetes mellitus and obese participants without diabetes
}

\author{
Noémi Tóth ${ }^{1,2,3} \cdot$ David M. Silver ${ }^{4}$ Szabolcs Balla ${ }^{2} \cdot$ Miklós Káplár $^{5} \cdot$ Adrienne Csutak $^{1,2,3}$ (1)
}

Received: 28 January 2021 / Revised: 7 May 2021 / Accepted: 19 May 2021 / Published online: 20 July 2021

(c) The Author(s) 2021

\begin{abstract}
Purposes To examine corneal nerve and retinal nerve characteristics of participants with type 2 diabetes mellitus (T2DM) compared with obese participants without diabetes to discover potential nerve vulnerabilities.

Methods All participants underwent a complete medical examination including a physical examination and blood sample tests. The ophthalmologic examination included best-corrected visual acuity, intraocular pressure, Schirmer test, tear film breakup time, slit-lamp examination, dilated fundus photography, in vivo corneal confocal microscopy (IVCCM), and optical coherence tomography (OCT). Results The study cohort consisted of 83 eyes of 83 individuals: a group of 44 participants with T2DM, and a control group of 39 obese participants with no history of diabetes. Comparing measurements on the two groups, participants with T2DM had lower values with statistical significance for retinal nerve fiber layer (RNFL) nasal superior thickness $(p=0.010)$ and three corneal nerve (CN) parameters: fiber length $(p=0.025)$, total branch density $(p=0.013)$, and fiber area $(p=0.009)$. There was a borderline significant difference in $\mathrm{CN}$ fiber width $(p=0.051)$ and RNFL nasal inferior thickness $(p=0.056)$. No other significant differences were observed in the IVCCM and OCT parameters. No statistically significant correlation was found between CN and RNFL parameters. Conclusions Progression from a pre-diabetic obese state to a T2DM condition might entail a loss or diminishment of certain corneal nerve fibers or retinal nerve fibers, but not necessarily a loss of both corneal and retinal nerve fibers simultaneously. Using IVCCM and OCT together enables monitoring of both corneal and retinal health of the eye.
\end{abstract}

\section{Key messages}

- Diabetes can lead to diabetic keratopathy and retinopathy.

- Loss of certain corneal nerve and retinal nerve fiber integrity can develop, but not necessarily a simultaneous loss to both corneal and retinal nerve fibers.

- Both in vivo corneal confocal microscopy and optical coherence tomography are useful for monitoring potential damage to the cornea and retina of eyes of obese individuals and those with diabetes.

Keywords Type 2 diabetes mellitus · Obesity · In vivo confocal corneal microscopy · OCT

Adrienne Csutak

csutak.adrienne@pte.hu

1 Department of Ophthalmology, University of Pécs, Medical School, Akác u. 1, Pécs 7623, Hungary

2 Department of Ophthalmology, Faculty of Medicine, University of Debrecen, Debrecen 4032, Hungary
3 Doctoral School of Clinical Medicine, University of Debrecen, Debrecen 4032, Hungary

4 Johns Hopkins University, Bethesda, MA 20816, USA

5 Division of Metabolic Diseases, Department of Internal Medicine, Faculty of Medicine, University of Debrecen, Debrecen 4032, Hungary 


\section{Introduction}

Chronically existing hyperglycemia and consequential vascular complications are the main diabetic side effects causing mortality and disability [1]. Diabetes mellitus regularly results in corneal edema, erosions and changes of the tear film, and worsening corneal epithelial wound healing, despite the fact that it remains undetected clinically in almost $70 \%$ of the cases [2,3]. Neuropathy can be diagnosed at an early stage with in vivo corneal confocal microscopy (IVCCM), which is a non-invasive technique that allows the clinician to examine the layers of the cornea accurately [4-6]. In addition, optical coherence tomography (OCT) plays a key role in identifying and quantifying the grade of maculopathy in diabetes mellitus [7]. Attention has also been focused on retinal nerve fiber layer (RNFL) and choroidal layer thickness measurements [8-10].

In a previous work, RNFL thickness has been associated with a range of health and lifestyle parameters [11]. Reduced corneal nerve fiber size has been observed in people with diabetes [12-14]. IVCCM on individuals with type 2 diabetes mellitus (T2DM) has demonstrated increased Langerhans cells and decreased sub-basal nerve plexus that may be related to lower basal endothelial cell density and may be responsible for corneal epithelium healing delay [15].

The aim of this study was to examine the differences between corneal and retinal nerve fiber characteristics of participants with T2DM compared with obese controls without diabetes using IVCCM and OCT to discover potential nerve vulnerabilities accompanying diabetes and obesity.

\section{Participants and methods}

\section{Study participants}

The study cohort consisted of 83 eyes of 83 individuals: a group of 44 participants with T2DM, 26 males and 18 females; and a control group of 39 obese participants with no history of diabetes, 16 males and 23 females. The eyes of all individuals were examined in the Ophthalmology Department, Faculty of Medicine, University of Debrecen. When both eyes were suitable for the study, one was chosen randomly. Inclusion and exclusion criteria are listed in Table 1.

Ethical permission was granted by the University of Debrecen Ethics Committee (No. OGYÉI/2829/2017) and all participants provided written informed consent in accordance with the Helsinki Declaration.

\section{Clinical and ophthalmological investigations}

All participants underwent a complete medical examination including a physical examination and blood sample tests. Tabulated values for the 83 participants included age, body mass index (BMI), glycated hemoglobin (HbAlc), glucose, triglyceride, cholesterol, high-density lipoprotein (HDL), and low-density lipoprotein (LDL). The ophthalmologic examination included best-corrected visual acuity (BCVA), intraocular pressure (IOP), Schirmer test, tear film breakup time (BUT), slit-lamp examination, dilated fundus photography, IVCCM, and OCT.

\section{In vivo corneal confocal microscopy}

Heidelberg Retina Tomograph III Rostock Cornea Module (HRT III RCM, Heidelberg Engineering GmbH, Heidelberg, Berlin, Germany) was used during the IVCCM analysis. Tetracaine hydrochloride $0.5 \%$ was administered as local anesthesia and the participant was focusing on a distant target before the central cornea was scanned. Section and volume scans were recorded from the basal epithelium anterior to Bowman's layer, sub-basal nerve plexus, posterior stroma anterior to Descemet's membrane, and endothelial cells. These observations did not include the morphology or density of Langerhans cells. Three representative corneal confocal microscopy (CCM) images were chosen for analysis, (a) basal epithelium (epithelial cells), (b) average of anterior and posterior stromal keratocytes (stromal keratocytes), and (c) endothelial cell layers (endothelial cells), all measured in number $/ \mathrm{mm}^{2}$. A region of interest was defined as containing at least 50 cells, which were chosen from each cell layer. At least 5 , on average 8 , good quality [16] pictures from the central area were used to evaluate the sub-basal nerve plexus, not overlapping more than $20 \%$.

The cells were identified and marked manually and the cell densities were automatically calculated by the instrument-based software (Heidelberg Eye Explorer software, Heidelberg Engineering GmbH, Heidelberg, Berlin, Germany). ACCMetrics software (version 2.0; University of

Table 1 Inclusion and exclusion criteria for participation in the study

\begin{tabular}{ll}
\hline Inclusion criteria & Exclusion criteria \\
\hline Written informed consent form & Previous intraocular surgery \\
Age $>18$ years & Glaucoma \\
BCVA $=20 / 20 \mathrm{ft}$. (Snellen) & Contact lens wear \\
T2DM group: diabetes diagnosis & Diabetic maculopathy \\
Obese group: BMI $>30.0 \mathrm{~kg} / \mathrm{m}^{2}$ & Proliferative diabetic retinopathy \\
\hline
\end{tabular}

$B C V A$ best-corrected visual acuity, T2DM type 2 diabetes mellitus, $B M I$ body mass index 
Manchester, Manchester, UK) [17] was used to evaluate the morphology of the sub-basal nerve plexus. The execution and analysis of the examinations were performed by one masked examiner.

The following corneal nerve $(\mathrm{CN})$ parameters were quantified: $\mathrm{CN}$ fiber density, the number of nerve fibers per unit area; $\mathrm{CN}$ branch density, the number of primary branch fibers per unit area; $\mathrm{CN}$ fiber length, the total length of nerves per unit area; $\mathrm{CN}$ total branch density, the total number of branch points per unit area; $\mathrm{CN}$ fiber area, the total nerve fiber area per unit area; $\mathrm{CN}$ fiber width, the average nerve fiber width per unit area; and $\mathrm{CN}$ fractal dimension.

\section{Optical coherence tomography}

Retina scans were acquired with the SPECTRALIS OCT system (Heidelberg Engineering, Heidelberg, Germany). Volume scans (49 line, $30^{\circ}$, HS, ART 16) were performed for multi-segment volume measurements for foveal volume at the central $6 \mathrm{~mm}$ area. Line scans $\left(30^{\circ}\right.$, HR, ART 50) were used with enhanced depth imaging (EDI) for central retinal thickness, choroidal layer thickness, and built-in RNFL thickness measurements using the manual correction option for ideal centering on the optic nerve head. All examinations were performed and evaluated by one examiner. The built-in RNFL parameters were global thickness, temporal, temporal inferior, temporal superior, nasal, nasal inferior, and nasal superior.

\section{Statistical analysis}

A total of 1909 ophthalmic measurements (23 measurement categories on each of 83 individuals) were considered in this work. Of these, 70 measurements were missing (measurement was not made) and 11 measurements were outliers that did not satisfy the Grubbs criteria [18] for inclusion, leaving 1828 measurements for further analysis. There were 664 non-ophthalmic measurements ( 8 categories on each of 83 participants) of which 8 measurements were missing and 7 measurements were outliers, giving 649 reliable measurements. In addition, age and gender were recorded. Normal distribution of samples within each measurement category was tested with analysis of residuals from a normal plot [19]. Equivalence of measurements within a given measurement category between T2DM and obese groups were tested with $t$ tests, Mann-Whitney U tests, and one-way analysis of variance [20]; since these three analyses gave equivalent results, $t$ tests were chosen to display herein. For correlation analyses, each pair of measurement categories was reduced to the minimum pairwise number of measurements in the pair. The Pearson product-moment correlation coefficient was used with the $t$ test for statistical significance. Statistical significance was defined as $p<0.05$.

\section{Results}

\section{Demographic and clinical data}

Age and BMI distributions among the two study groups are shown in Table 2. Participants in the obese group had highly significant $(p<0.001)$ increased BMI compared to participants with T2DM. Nevertheless, two-thirds of the participants with T2DM had BMI greater than $30 \mathrm{~kg} / \mathrm{m}^{2}$, which would qualify them as obese.

The results of blood sample measurements of $\mathrm{HbA} 1 \mathrm{c}$ and glucose are displayed in Table 3 and the distribution of measurements is shown in Figs. 1 and 2, illustrating the difference between people with diabetes and those who are obese without diabetes. Eighteen of the diabetic patients were on insulin therapy but nevertheless had elevated HbA1c values.

HbA1c and glucose levels were higher for people in the T2DM group with the difference having high statistical significance $(p<0.001)$. Comparing the HbA1c measurements to standard reference ranges, $17 \%$ of people with T2DM and $90 \%$ of the people in the obese group had HbA1c below $42 \mathrm{mmol} / \mathrm{mol} ; 12 \%$ with T2DM and $10 \%$
Table 2 Age and body mass index of participants with type 2 diabetes mellitus (T2DM) and the obese control group without diabetes

\begin{tabular}{|c|c|c|c|c|c|c|}
\hline & \multicolumn{3}{|c|}{ Age (years) } & \multicolumn{3}{|c|}{ Body mass index $\left(\mathrm{kg} / \mathrm{m}^{2}\right)$} \\
\hline & $\mathrm{T} 2 \mathrm{DM}$ & Obese & $p$ value & T2DM & Obese & $p$ value \\
\hline Mean & 50 & 53 & & 33.2 & 38.6 & \\
\hline Std. Dev. & 7 & 10 & & 5.2 & 6.10 & \\
\hline Maximum & 63 & 67 & 0.221 & 47.3 & 54.50 & $<0.001$ \\
\hline Median & 51 & 52 & & 32.4 & 36.5 & \\
\hline Minimum & 33 & 32 & & 24.6 & 31.0 & \\
\hline Number & 44 & 39 & & 43 & 39 & \\
\hline
\end{tabular}

The $p$ values were calculated using $t$ tests

Bold values denote statistical significance at the $p<0.05$ level 
Table 3 Blood sample measurements of participants with type 2 diabetes mellitus (T2DM) and the obese control group without diabetes

\begin{tabular}{|c|c|c|c|c|c|c|c|c|}
\hline & \multicolumn{5}{|l|}{$\mathrm{HbA} 1 \mathrm{c}$} & \multirow{2}{*}{\multicolumn{2}{|c|}{$\frac{\text { Glucose }}{(\mathrm{mmol} / \mathrm{L})}$}} & \multirow[b]{3}{*}{$p$ value } \\
\hline & \multicolumn{2}{|c|}{$(\mathrm{mmol} / \mathrm{mol})$} & \multicolumn{2}{|l|}{$(\%)$} & \multirow[b]{2}{*}{$p$ value } & & & \\
\hline & $\mathrm{T} 2 \mathrm{DM}$ & Obese & $\mathrm{T} 2 \mathrm{DM}$ & Obese & & $\mathrm{T} 2 \mathrm{DM}$ & Obese & \\
\hline Mean & 56 & 37 & 7.3 & 5.5 & & 8.5 & 5.5 & \\
\hline Std. Dev. & 12 & 4 & 1.1 & 0.3 & & 2.7 & 0.6 & \\
\hline Maximum & 85 & 45 & 9.9 & 6.3 & $<0.001$ & 15.8 & 6.9 & $<0.001$ \\
\hline Median & 55 & 37 & 7.2 & 5.5 & & 8.1 & 5.4 & \\
\hline Minimum & 33 & 30 & 5.2 & 4.9 & & 4.9 & 4.7 & \\
\hline Number & 42 & 39 & 42 & 39 & & 43 & 39 & \\
\hline
\end{tabular}

The $p$ values were calculated using $t$ tests

Bold values denote statistical significance at the $p<0.05$ level obese had $\mathrm{HbA} 1 \mathrm{c}$ in the range $42-47 \mathrm{mmol} / \mathrm{mol}$; and $71 \%$ with T2DM and $0 \%$ obese had HbA1c above $47 \mathrm{mmol} /$ mol. Comparing glucose measurements to reference ranges, $7 \%$ of people with T2DM and $62 \%$ of obese controls had glucose below $5.6 \mathrm{mmol} / \mathrm{L} ; 26 \%$ with T2DM and $38 \%$ of obese had glucose in the range $(5.6,6.9) \mathrm{mmol} / \mathrm{L}$; and $67 \%$ with T2DM and $0 \%$ of obese had glucose above $6.9 \mathrm{mmol} / \mathrm{L}$. Measurements for both T2DM and obese groups had significant positive correlation between $\mathrm{HbA} 1 \mathrm{c}$ and glucose: $r=0.73$ with $p<0.001$ for the T2DM group and $r=0.37$ with $p=0.020$ for the obese group.

Further blood sample measurements are shown in Table 4. Cholesterol level was lower $(p=0.021)$, HDL level was lower $(p=0.047)$, and LDL level was lower

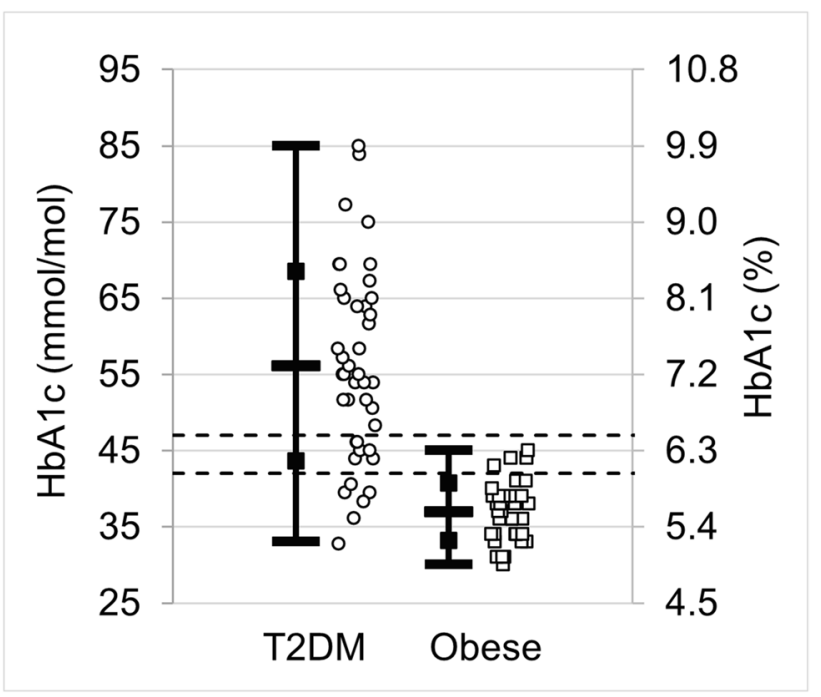

Fig. 1 Measurements of HbA1c (left scale: $\mathrm{mmol} / \mathrm{mol}$, right scale: $\%$ ) for the participants with type 2 diabetes mellitus (T2DM) and the obese control group without diabetes. The open bars on vertical lines indicate the mean value, open squares indicate \pm standard deviation, and solid bars indicate minimum and maximum values. The raw data are shown scattered horizontally for clarity. Dashed lines are drawn at 42 and $47 \mathrm{mmol} / \mathrm{mol}$ (6.0 and 6.5\%). T2DM, $N=42$; obese, $N=39$ $(p<0.001)$ for people in the T2DM group, while the triglyceride level was not significantly different $(p=0.221)$ between the two groups. Compared to reference ranges, $35 \%$ of people in the T2DM group and $51 \%$ of the obese group had cholesterol greater than $5.2 \mathrm{mmol} / \mathrm{L}, 33 \%$ of T2DM and $18 \%$ of obese had HDL less than $1.03 \mathrm{mmol} / \mathrm{L}$, and $39 \%$ of people in the T2DM group and $70 \%$ of the obese group had LDL greater than $3.3 \mathrm{mmol} / \mathrm{L}$. The measurements on people in both groups showed significant positive correlation between cholesterol and LDL, $r>0.87$ with $p<0.001$, and significant negative correlation

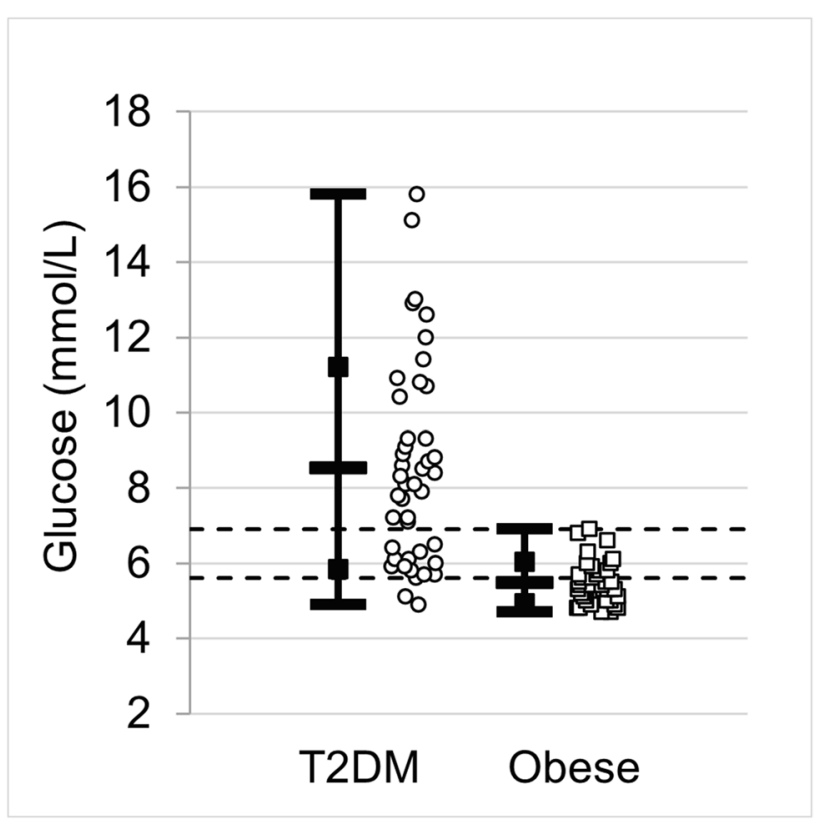

Fig. 2 Measurements of glucose $(\mathrm{mmol} / \mathrm{L})$ for the participants with type 2 diabetes mellitus (T2DM) and the obese control group without diabetes. The open bars on vertical lines indicate the mean value, open squares indicate \pm standard deviation, and solid bars indicate minimum and maximum values. The raw data are shown scattered horizontally for clarity. Dashed lines are drawn at 5.6 and $6.9 \mathrm{mmol} / \mathrm{L}$. T2DM, $N=43$; obese, $N=39$ 
Table 4 Cholesterol, triglyceride, high-density lipoprotein (HDL), and lowdensity lipoprotein (LDL) measurements of participants with type 2 diabetes mellitus (T2DM) and the obese control group without diabetes

\begin{tabular}{lllllll}
\hline & Cholesterol $(\mathrm{mmol} / \mathrm{L})$ & & & Triglyceride $(\mathrm{mmol} / \mathrm{L})$ & & \\
& T2DM & Obese & $p$ value & T2DM & Obese & $p$ value \\
Mean & 4.97 & 5.56 & & 2.00 & 1.70 & \\
Std. Dev. & 0.98 & 1.25 & & 1.37 & 0.70 & \\
Maximum & 7.70 & 9.50 & $\mathbf{0 . 0 2 1}$ & 5.90 & 3.50 & 0.221 \\
Median & 5.00 & 5.40 & & 1.50 & 1.40 & \\
Minimum & 2.80 & 3.20 & & 0.40 & 0.70 & \\
Number & 43 & 39 & & 40 & 39 & \\
& HDL (mmol/L) & & & LDL $(\mathrm{mmol} / \mathrm{L})$ & & \\
& T2DM & Obese & $p$ value & T2DM & Obese & $p$ value \\
Mean & 1.24 & 1.38 & & 3.03 & 3.69 & \\
Std. Dev. & 0.31 & 0.33 & & 0.81 & 0.83 & \\
Maximum & 2.00 & 2.00 & $\mathbf{0 . 0 4 7}$ & 4.40 & 6.00 & $<\mathbf{0 . 0 0 1}$ \\
Median & 1.30 & 1.40 & & 3.10 & 3.50 & \\
Minimum & 0.60 & 0.80 & & 1.10 & 2.00 & \\
Number & 42 & 39 & & 41 & 37 & \\
\hline
\end{tabular}

The $p$ values were calculated using $t$ tests

Bold values denote statistical significance at the $p<0.05$ level between triglyceride and HDL, $r<-0.45$ with $p<0.005$. The measurements on people in the T2DM group had a significant correlation between cholesterol and triglyceride, $r=0.33$ with $p=0.042$. The measurements on people in the obese group had significant correlations between cholesterol and HDL, $r=0.58$ with $p<0.001$, and between HDL and LDL, $r=0.45$ with $p=0.005$.

Table 5 displays clinical ophthalmic parameters. Between the two groups of participants, there were no significant differences in the Schirmer test or BUT, while the mean value of IOP was higher $(p=0.022)$ for people in the T2DM group. However, all three of these ophthalmic measurements were considered within normal limits.

\section{Corneal nerve cell densities and corneal sub-basal plexus}

The IVCCM data for the two groups of participants are summarized in Table 6 . There were no significant differences in epithelial cell, stromal keratocyte, or endothelial cell densities (all $p>0.132$ ) between T2DM and obese groups. In the T2DM group, the $\mathrm{CN}$ fiber length $(p=0.025), \mathrm{CN}$ total branch density $(p=0.013)$, and $\mathrm{CN}$ fiber area $(p=0.009)$ values were significantly lower; there was a borderline significant difference in $\mathrm{CN}$ fiber width $(p=0.051)$; and no difference was seen in CN fiber density $(p=0.550), \mathrm{CN}$ branch density $(p=0.088)$, and $\mathrm{CN}$ fractal dimension $(p=0.093)$. Among these corneal parameters, there were positive correlations among several pairs of $\mathrm{CN}$ fiber density, $\mathrm{CN}$ branch density, $\mathrm{CN}$ fiber length, $\mathrm{CN}$ total branch density, $\mathrm{CN}$ fiber area, and $\mathrm{CN}$ fractal dimension: $0.49<r<0.94$ with $p<0.002$ for measurements in the T2DM group and $0.59<r<0.93$ with $p<0.019$ for the obese group. The exception was $\mathrm{CN}$ fiber width that had negative correlation with $\mathrm{CN}$ fiber density for T2DM, $r=-0.48$ with $p=0.001$, and with $\mathrm{CN}$ branch density for obese, $r=-0.40$ with $p=0.019$. Pairwise, $\mathrm{CN}$ fiber
Table 5 Ophthalmic clinical parameters of participants with type 2 diabetes mellitus (T2DM) and the obese control group without diabetes

\begin{tabular}{|c|c|c|c|c|c|c|c|c|c|}
\hline & \multicolumn{3}{|c|}{ Intraocular pressure $(\mathrm{mmHg})$} & \multicolumn{3}{|c|}{ Schirmer test $(\mathrm{mm} / 5 \mathrm{~min})$} & \multicolumn{3}{|c|}{ Tear film breakup time (sec) } \\
\hline & $\mathrm{T} 2 \mathrm{DM}$ & Obese & $p$ value & $\mathrm{T} 2 \mathrm{DM}$ & Obese & $p$ value & $\mathrm{T} 2 \mathrm{DM}$ & Obese & $p$ value \\
\hline Mean & 16.9 & 15.3 & & 10.9 & 8.8 & & 6.8 & 8.6 & \\
\hline Std. Dev. & 2.6 & 3.7 & & 10.7 & 6.2 & & 4.2 & 5.4 & \\
\hline Maximum & 23.0 & 21.0 & 0.022 & 36.0 & 26.0 & 0.317 & 18.0 & 21.0 & 0.079 \\
\hline Median & 17.0 & 15.0 & & 6.5 & 8.0 & & 6.5 & 8.0 & \\
\hline Minimum & 12.0 & 8.0 & & 1.0 & 1.0 & & 1.0 & 1.0 & \\
\hline Number & 44 & 39 & & 38 & 33 & & 44 & 38 & \\
\hline
\end{tabular}

The $p$ values were calculated using $t$ tests

Bold values denote statistical significance at the $p<0.05$ level 
Table 6 In vivo corneal confocal microscopy (IVCCM) measurements of corneal confocal microscopy images and corneal nerve (CN) properties of participants with type 2 diabetes mellitus (T2DM) and the obese control group without diabetes

\begin{tabular}{|c|c|c|c|c|c|c|c|c|c|}
\hline & \multicolumn{3}{|c|}{ Epithelial cell density (number $/ \mathrm{mm}^{2}$ ) } & \multicolumn{3}{|c|}{ Stromal keratocyte density (number $/ \mathrm{mm}^{2}$ ) } & \multicolumn{3}{|c|}{ Endothelial cell density (number/mm²) } \\
\hline & T2DM & Obese & $p$ value & T2DM & Obese & $p$ value & T2DM & Obese & $p$ value \\
\hline Mean & 6622 & 6726 & & 387.6 & 441.9 & & 3285 & 3544 & \\
\hline Std. Dev. & 778 & 906 & & 110.5 & 115.4 & & 791 & 709 & \\
\hline Maximum & 8083 & 8911 & 0.580 & 665.0 & 686.2 & 0.221 & 5551 & 5044 & 0.132 \\
\hline Median & 6766 & 6674 & & 359.3 & 441.3 & & 3073 & 3645 & \\
\hline Minimum & 5320 & 4623 & & 202.0 & 216.0 & & 1943 & 2171 & \\
\hline \multirow[t]{3}{*}{ Number } & 43 & 38 & & 43 & 39 & & 42 & 37 & \\
\hline & \multicolumn{3}{|c|}{$\mathrm{CN}$ fiber density (fibers $/ \mathrm{mm}^{2}$ ) } & \multicolumn{3}{|c|}{$\mathrm{CN}$ branch density (fibers $/ \mathrm{mm}^{2}$ ) } & \multicolumn{3}{|c|}{$\mathrm{CN}$ fiber length $\left(\mathrm{mm} / \mathrm{mm}^{2}\right)$} \\
\hline & T2DM & Obese & $p$ value & T2DM & Obese & $p$ value & T2DM & Obese & $p$ value \\
\hline Mean & 12.05 & 12.93 & & 12.43 & 16.49 & & 9.61 & 11.27 & \\
\hline Std. Dev. & 6.25 & 6.83 & & 8.09 & 12.06 & & 3.16 & 3.39 & \\
\hline Maximum & 26.25 & 29.54 & 0.550 & 31.25 & 45.00 & 0.088 & 14.83 & 20.01 & 0.025 \\
\hline Median & 11.87 & 11.46 & & 9.82 & 13.75 & & 10.11 & 10.14 & \\
\hline Minimum & 1.56 & 2.50 & & 2.68 & 1.04 & & 1.42 & 6.31 & \\
\hline \multirow[t]{3}{*}{ Number } & 42 & 37 & & 40 & 35 & & 44 & 37 & \\
\hline & \multicolumn{3}{|c|}{$\begin{array}{l}\mathrm{CN} \text { total branch density (branch points/ } \\
\mathrm{mm}^{2} \text { ) }\end{array}$} & \multicolumn{3}{|c|}{$\mathrm{CN}$ fiber area $\left(\mathrm{mm}^{2} / \mathrm{mm}^{2}\right)$} & \multicolumn{3}{|c|}{$\mathrm{CN}$ fiber width $\left(\mathrm{mm} / \mathrm{mm}^{2}\right)$} \\
\hline & $\mathrm{T} 2 \mathrm{DM}$ & Obese & $p$ value & T2DM & Obese & $p$ value & T2DM & Obese & $p$ value \\
\hline Mean & 24.66 & 32.78 & & 0.00491 & 0.00587 & & 0.0229 & 0.0223 & \\
\hline Std. Dev. & 12.37 & 16.04 & & 0.00150 & 0.00168 & & 0.0017 & 0.0010 & \\
\hline Maximum & 51.78 & 69.88 & 0.013 & 0.00824 & 0.01017 & 0.009 & 0.0277 & 0.0245 & 0.051 \\
\hline Median & 22.41 & 27.08 & & 0.00482 & 0.00543 & & 0.0228 & 0.0223 & \\
\hline Minimum & 3.12 & 11.80 & & 0.00130 & 0.00293 & & 0.0193 & 0.0199 & \\
\hline \multirow[t]{3}{*}{ Number } & 44 & 36 & & 44 & 36 & & 44 & 36 & \\
\hline & \multicolumn{9}{|c|}{$\mathrm{CN}$ fractal dimension } \\
\hline & T2DM & Obese & $p$ value & & & & & & \\
\hline Mean & 1.427 & 1.445 & & & & & & & \\
\hline Std. Dev. & 0.049 & 0.042 & & & & & & & \\
\hline Maximum & 1.502 & 1.518 & 0.093 & & & & & & \\
\hline Median & 1.439 & 1.441 & & & & & & & \\
\hline Minimum & 1.307 & 1.349 & & & & & & & \\
\hline Number & 43 & 37 & & & & & & & \\
\hline
\end{tabular}

The $p$ values were calculated using $t$ tests

Bold values denote statistical significance at the $p<0.05$ level

length, $\mathrm{CN}$ total branch density, and $\mathrm{CN}$ fiber area are significantly positive correlated with each other, $0.69<r<0.76$ with $p<0.001$ for people with T2DM and $0.85<r<0.89$ with $p<0.001$ for obese. $\mathrm{CN}$ fiber width is not significantly correlated with $\mathrm{CN}$ fiber length, $\mathrm{CN}$ total branch density, or $\mathrm{CN}$ fiber area.

\section{Retinal nerve measurements}

The OCT measurements are summarized in Table 7. Neither central retinal thickness nor RNFL values showed any differences between the T2DM and obese groups, except for a significant difference in RNFL nasal superior thickness $(p=0.010)$ and a borderline difference for RNFL nasal inferior thickness $(p=0.056)$. Foveal volume and choroidal thickness were not different between T2DM and obese groups. Among these OCT parameters, there were significant positive correlations $(p<0.05)$ between several of the pairs of the seven RNFL parameters and foveal volume in both T2DM and obese groups: $0.35<r<0.75$ with $p<0.038$. For the T2DM group, RNFL nasal superior was significantly correlated with RNFL global thickness, RNFL temporal superior, RNFL nasal, RNFL nasal inferior, and foveal volume: $0.35<r<0.63$ with $p<0.019$. For the obese group, RNFL nasal superior was significantly correlated only with RNFL global thickness: $r=0.48$ with $p=0.003$. 
Table 7 Optical coherence tomography (OCT) measurements of retinal nerve fiber layer (RNFL) properties of participants with type 2 diabetes mellitus (T2DM) and the obese control group without diabetes

\begin{tabular}{|c|c|c|c|c|c|c|c|c|c|}
\hline & \multicolumn{3}{|c|}{ Central retinal thickness $(\mu \mathrm{m})$} & \multicolumn{3}{|c|}{ Central choroidal thickness $(\mu \mathrm{m})$} & \multicolumn{3}{|c|}{ RNFL global thickness $(\mu \mathrm{m})$} \\
\hline & $\mathrm{T} 2 \mathrm{DM}$ & Obese & $p$ value & $\mathrm{T} 2 \mathrm{DM}$ & Obese & $p$ value & $\mathrm{T} 2 \mathrm{DM}$ & Obese & $p$ value \\
\hline Mean & 275.0 & 272.05 & & 249.7 & 227.4 & & 100.0 & 104.4 & \\
\hline Std. Dev. & 16.6 & 23.60 & & 44.4 & 37.9 & & 11.5 & 10.3 & \\
\hline Maximum & 316.0 & 322.0 & 0.505 & 345.0 & 283.0 & 0.064 & 121.0 & 132.0 & 0.066 \\
\hline Median & 278.0 & 273.0 & & 242.5 & 233.5 & & 102.5 & 103.0 & \\
\hline Minimum & 240.0 & 225.0 & & 165.0 & 135.0 & & 75.0 & 76.0 & \\
\hline \multirow[t]{3}{*}{ Number } & 43 & 39 & & 30 & 22 & & 44 & 39 & \\
\hline & \multicolumn{3}{|c|}{ RNFL temporal superior $(\mu \mathrm{m})$} & \multicolumn{3}{|c|}{ RNFL temporal $(\mu \mathrm{m})$} & \multicolumn{3}{|c|}{ RNFL temporal inferior $(\mu \mathrm{m})$} \\
\hline & T2DM & Obese & $p$ value & T2DM & Obese & $p$ value & $\mathrm{T} 2 \mathrm{DM}$ & Obese & $p$ value \\
\hline Mean & 139.6 & 144.6 & & 67.5 & 68.6 & & 142.6 & 144.6 & \\
\hline Std. Dev. & 19.2 & 22.5 & & 10.6 & 9.7 & & 20.6 & 16.7 & \\
\hline Maximum & 176.0 & 190.0 & 0.271 & 96.0 & 86.0 & 0.634 & 200.0 & 183.0 & 0.636 \\
\hline Median & 139.5 & 147.0 & & 67.0 & 71.0 & & 142.5 & 145.0 & \\
\hline Minimum & 99.0 & 102.0 & & 46.0 & 48.0 & & 94.0 & 117.0 & \\
\hline \multirow[t]{3}{*}{ Number } & 44 & 39 & & 44 & 39 & & 44 & 39 & \\
\hline & \multicolumn{3}{|c|}{ RNFL nasal superior $(\mu \mathrm{m})$} & \multicolumn{3}{|c|}{ RNFL nasal $(\mu \mathrm{m})$} & \multicolumn{3}{|c|}{ RNFL nasal inferior $(\mu \mathrm{m})$} \\
\hline & $\mathrm{T} 2 \mathrm{DM}$ & Obese & $p$ value & T2DM & Obese & $p$ value & $\mathrm{T} 2 \mathrm{DM}$ & Obese & $p$ value \\
\hline Mean & 112.1 & 123.4 & & 77.9 & 79.5 & & 113.6 & 123.2 & \\
\hline Std. Dev. & 19.9 & 18.2 & & 15.1 & 13.3 & & 24.0 & 20.6 & \\
\hline Maximum & 152.0 & 166.0 & 0.010 & 118.0 & 107.0 & 0.606 & 170.0 & 167.0 & 0.056 \\
\hline Median & 112.0 & 123.0 & & 76.0 & 79.5 & & 111.0 & 121.0 & \\
\hline Minimum & 79.0 & 82.0 & & 52.0 & 44.0 & & 73.0 & 68.0 & \\
\hline \multirow[t]{3}{*}{ Number } & 44 & 37 & & 44 & 38 & & 44 & 39 & \\
\hline & \multicolumn{9}{|c|}{ Foveal volume $6 \mathrm{~mm}\left(\mathrm{~mm}^{3}\right)$} \\
\hline & $\mathrm{T} 2 \mathrm{DM}$ & Obese & $p$ value & & & & & & \\
\hline Mean & 8.61 & 8.55 & & & & & & & \\
\hline Std. Dev. & 0.38 & 0.31 & & & & & & & \\
\hline Maximum & 9.29 & 9.12 & 0.452 & & & & & & \\
\hline Median & 8.59 & 8.60 & & & & & & & \\
\hline Minimum & 7.78 & 7.91 & & & & & & & \\
\hline Number & 44 & 39 & & & & & & & \\
\hline
\end{tabular}

The $p$ values were calculated using $t$ tests

Bold values denote statistical significance at the $p<0.05$ level

\section{Discussion}

Considering the two groups of participants in this study, obesity might eventually lead to the development of T2DM through insulin resistance [21]. Obese study participants who regularly took antidiabetics, such as metformin, might be present with impaired glucose tolerance (IGT); however, we did not examine the presence of IGT in our obese cohort, neither did we take into account its possible effects during data analysis. Another limitation of our study was the size of the study sample; however, according to our knowledge, a similar study was only done in animal model [23]. Larger future studies are warranted.

A measure of similarity between the two groups is that two-thirds of those with T2DM qualify as obese. However, as shown in Table 2, the difference between mean values of BMI of the T2DM and obese groups is statistically significant $(p<0.001)$. The HbA1c and glucose measurements shown in Table 3 and Figs. 1 and 2 identify strong differences between the groups $(p<0.001)$. Further differences between the groups appear in cholesterol and LDL measurements for the people who are obese without diabetes: $51 \%$ have cholesterol levels and $70 \%$ have LDL levels above normal values. Although the IOP mean values differ between the groups, the IOP, Schirmer test, and BUT are all within corresponding acceptable healthy range for both groups of participants.

There are no correlations at the significance level of $p<0.05$ between the ages of the participants and any of the other measurements in this study, nor between BMI 
and any of the other measurements, corresponding to the participants in both groups on a participant level. There is a significant positive correlation between $\mathrm{HbA} 1 \mathrm{c}$ and glucose values, but none of the other measurements in this study are correlated with either HbA1c or glucose at the significance level of $p<0.05$. Similarly, cholesterol, triglyceride, HDL, and LDL measurements exhibit some mutual correlations among each other, but none of these four lipid measurement categories have measurements that are correlated with any of the other measurements in this study at the significance level of $p<0.05$.

For example, to illustrate lack of correlation, Fig. 3 provides $\mathrm{HbA1c}$ measurements plotted along with BMI and RNFL nasal superior using all measurements concurrently available for the three measurement categories separately from both T2DM and obese groups. Figure 3 is drawn with participants, people with T2DM on the left and obese on the right, as the horizontal axis and all measurements are sorted in ascending order with respect to $\mathrm{HbA} 1 \mathrm{c}$. Figure 3 shows that neither BMI nor RNFL nasal superior are correlated with the $\mathrm{HbA} 1 \mathrm{c}$ measurements; for instance, participants with higher $\mathrm{HbA1c}$ do not correspondently have higher BMI or RNFL nasal superior values.

For both T2DM and obese groups, there is significant correlation within the set of IVCCM measurements and separately within the set of OCT measurements. However, there is no significant correlation between IVCCM and OCT measurements at the significance level of $p<0.05$. This is illustrated in Fig. 4, where CN fiber density, $\mathrm{CN}$ fiber length, and RNFL nasal superior measurements are plotted, similarly to Fig. 3, except sorted in descending order with respect to $\mathrm{CN}$ fiber density. Figure 4 shows a strong correlation between $\mathrm{CN}$ fiber density and $\mathrm{CN}$ fiber length $(r=0.821, p<0.001$ for T2DM and $r=0.846, p<0.001$ for obese) and that RNFL nasal superior measurements are not correlated with the $\mathrm{CN}$ fiber density or $\mathrm{CN}$ fiber length measurements; for instance, participants with lower $\mathrm{CN}$ fiber density have lower $\mathrm{CN}$ fiber length but they do not correspondently have lower RNFL nasal superior values. Normative IVCCM measurements of some corneal nerve fiber characteristics have been reported [12, 22]. Mean values for $\mathrm{CN}$ fiber density, $\mathrm{CN}$ branch density, and $\mathrm{CN}$ fiber length, shown in Table 6, are lower for both the T2DM group and the obese group for all three properties compared with previous works [12, 22]. This is illustrated in Fig. 5 showing the distribution of $\mathrm{CN}$ fiber length measurements: the difference between the mean values of the T2DM and obese groups is statistically significant, $p=0.025$. Mean values of both the T2DM and obese groups are significantly different (lower) than the previously reported results [12, 22], $p<0.001$. The previous mean values $[12,22]$ are not statistically different from one another, $p=0.312$.

OCT mean values for RNFL temporal for both the T2DM and obese groups, shown in Table 7, are lower than those reported in previous researches [9-11]. However, the ranges of previously reported RNFL mean values for global, nasal, superior, and inferior are all lower than the corresponding mean values in Table 7. This is illustrated in Fig. 6

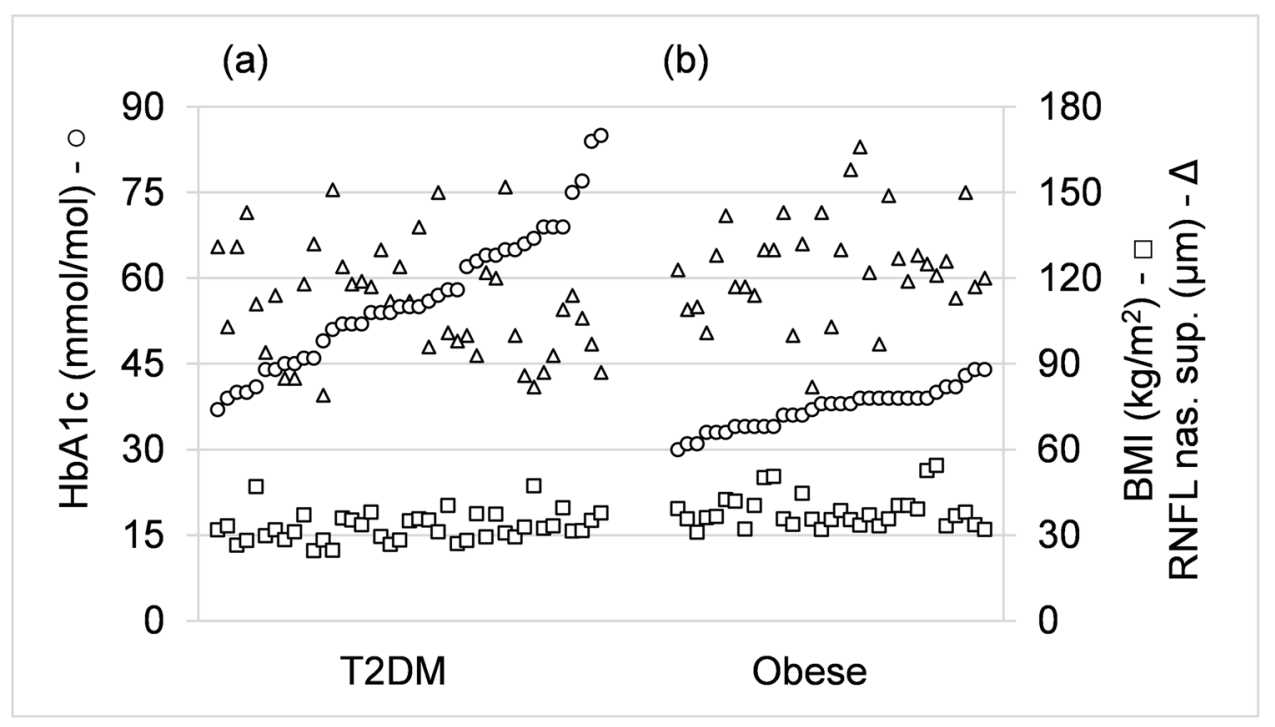

Fig. 3 Measurements of $\mathrm{HbAlc}(\mathrm{mmol} / \mathrm{mol})$, circles using left vertical scale, body mass index (BMI) $(\mathrm{kg} / \mathrm{m} 2)$, squares using right vertical scale, and retinal nerve fiber layer (RNFL) nasal superior $(\mu \mathrm{m})$, triangles using right vertical scale, for a participants with type 2 diabetes mellitus (T2DM) (on the left) and $\mathbf{b}$ those who are obese without diabetes (on the right). The three measurements corresponding to a particular individual are drawn on a vertical line and the measurements are sorted within each group in ascending order of $\mathrm{HbA} 1 \mathrm{c}$ along the horizontal axis. The resulting graph shows that $\mathrm{HbAlc}$, $\mathrm{BMI}$, and RNFL nasal superior are not mutually correlated (increased HbA1c is not accompanied by increases in BMI or RNFL nasal superior). T2DM, $N=41$; obese, $N=33$ 


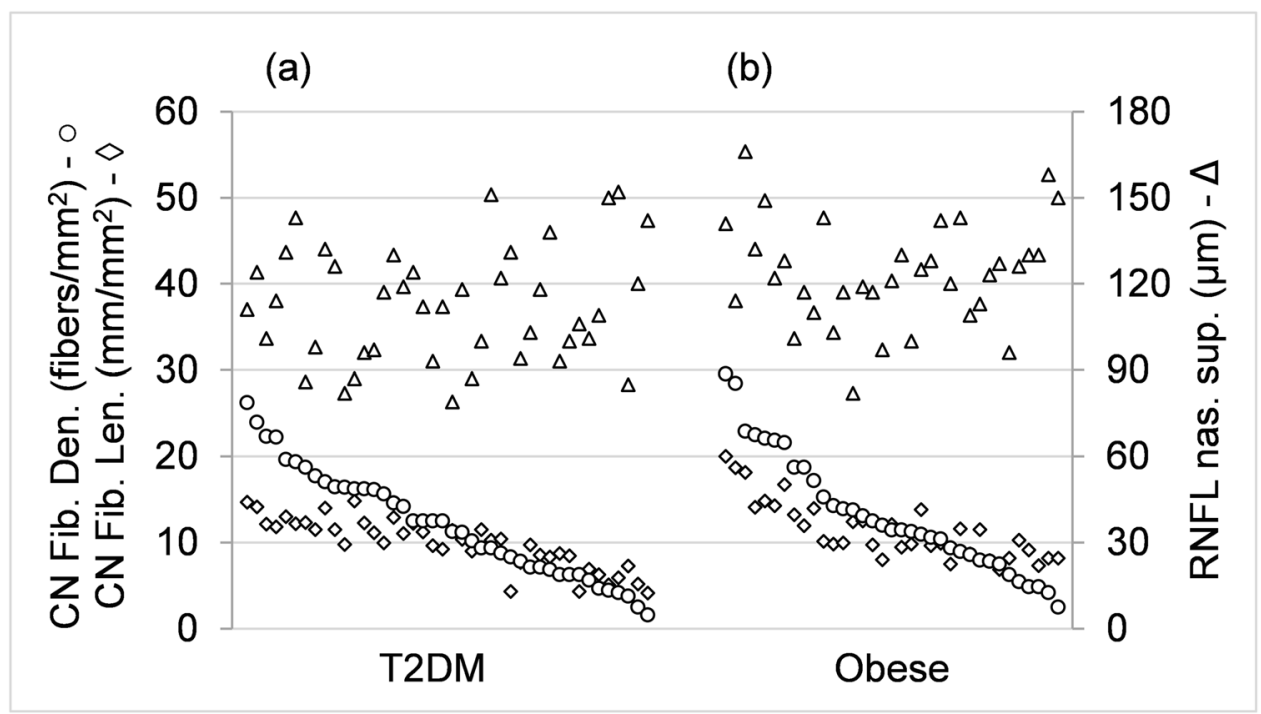

Fig. 4 Measurements of corneal nerve (CN) fiber density (fibers/ $\mathrm{mm} 2)$, circles on left vertical scale, $\mathrm{CN}$ fiber length $(\mathrm{mm} / \mathrm{mm} 2)$, diamonds on left vertical scale, and retinal nerve fiber layer (RNFL) nasal superior $(\mu \mathrm{m})$, triangles on right vertical scale for a participants with type 2 diabetes mellitus (T2DM) (on the left) and $\mathbf{b}$ those who are obese without diabetes on the right. The three measurements corresponding to a particular individual are drawn on a vertical line and

showing the distribution of RNFL global measurements. The mean values for the T2DM and obese groups are not significantly different, $p=0.066$, but both are significantly different (higher) than the previously reported results [9-11], $p<0.032$. the measurements are sorted within each group in descending order of $\mathrm{CN}$ fiber density along the horizontal axis. The results show that $\mathrm{CN}$ fiber density and $\mathrm{CN}$ fiber length are correlated but neither is correlated with RNFL nasal superior (decreases in CN fiber density are accompanied by a decrease in $\mathrm{CN}$ fiber length but not by a decrease in RNFL nasal superior). T2DM, $N=42$; obese, $N=35$

The results in Table 7 show that the RNFL difference between the T2DM and obese participants was significant in the nasal superior quadrant and borderline in the nasal inferior. However, the connection between diabetes, complications of diabetes, and RNFL thickness values have not

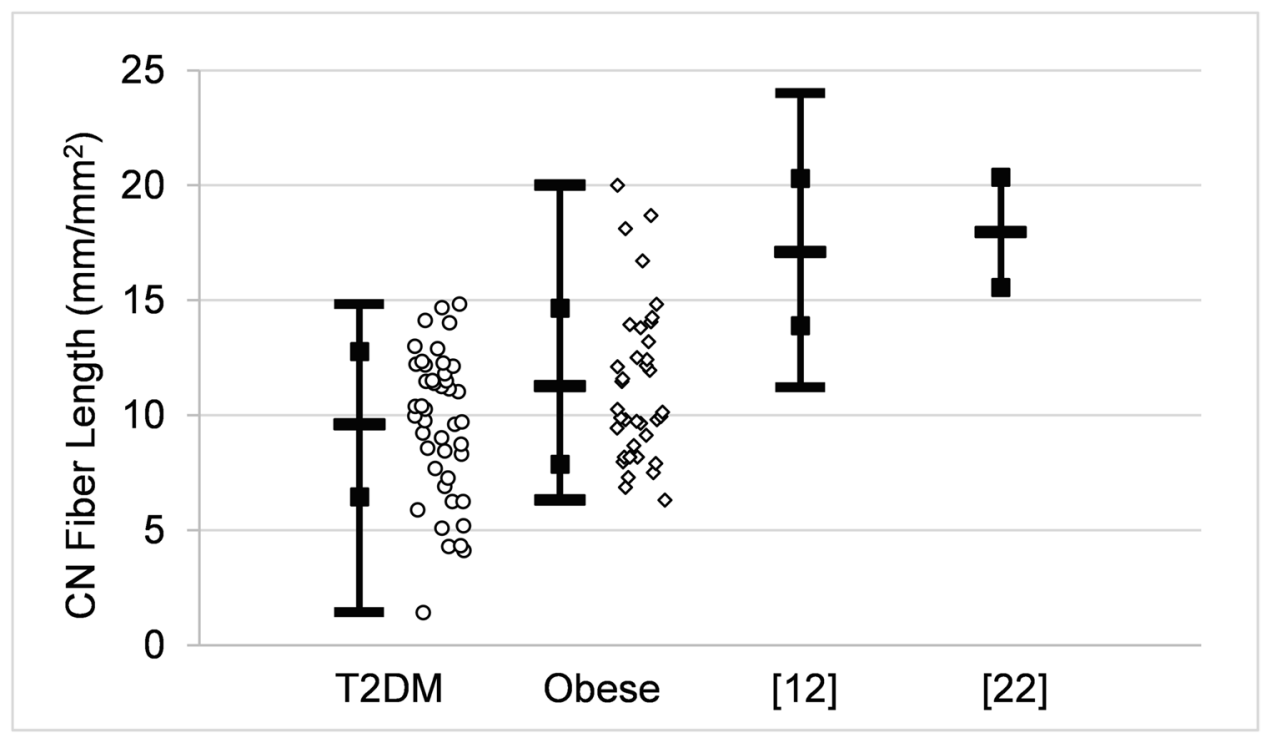

Fig. 5 Comparison of measurements of corneal nerve $(\mathrm{CN})$ fiber length $\left(\mathrm{mm} / \mathrm{mm}^{2}\right)$ for participants with type 2 diabetes mellitus (T2DM), circles, those who are obese without diabetes, diamonds, and two groups of people without diabetes or obesity from previous publications $[12,22]$. Where the information is available, the open bars on vertical lines indicate mean value, open squares indicate \pm standard deviation, and solid bars indicate minimum and maximum values. The raw data from the present work are shown scattered horizontally for clarity. T2DM, $N=44$; obese, $N=37 ;[12], N=48 ;$ [22], $N=12$ 


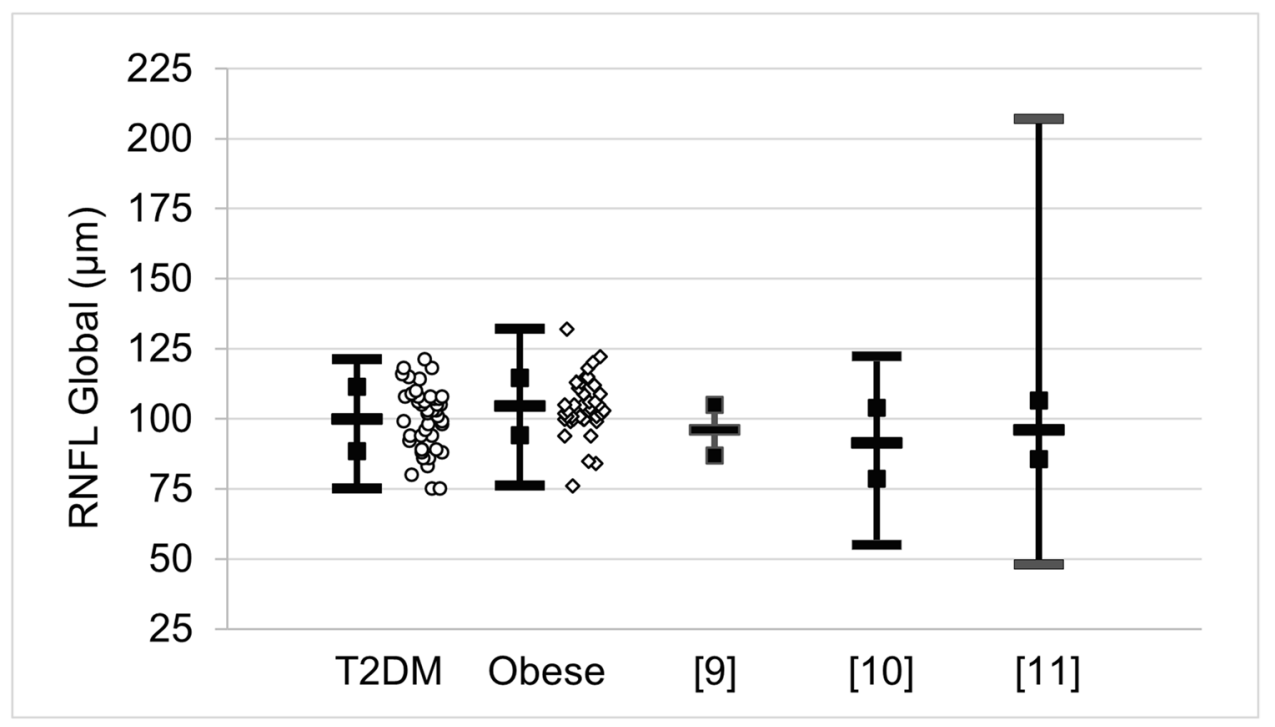

Fig. 6 Comparison of measurements of retinal nerve fiber layer (RNFL) global $(\mu \mathrm{m})$ for participants with type 2 diabetes mellitus (T2DM), circles, those who are obese without diabetes, diamonds, and three groups of people without diabetes or obesity from previous publications [9-11]. Where the information is available, the open bars

been fully elucidated to date. Some studies have shown multiple statistically significant relationships related to this issue $[24,25]$, but other studies have not [26], or just partially [27]. The roles of altered metabolic control and subclinical ischemia are presumed etiological factors in retinal neurodegeneration and axonal damages in T2DM [28]. OCT can be useful to detect these neurodegenerative changes, and as more and more information is gathered about the phenomenon, a better understanding of the process can make it easier to diagnose and assess progression and expected risk in complicated cases. In the present work using IVCCM and OCT, the analysis identifies four properties that show statistically significant differences between the mean values of measurements on people in the T2DM group and those in the obese control group: $\mathrm{CN}$ fiber length, $\mathrm{CN}$ total branch density, CN fiber area, and RNFL nasal superior. For each of the four properties, the measurement mean value for the T2DM group is less than that for the obese group, representing a possible degradation of nerve fiber status with diabetic state. However, $\mathrm{CN}$ fiber length, $\mathrm{CN}$ total branch density, and $\mathrm{CN}$ fiber area are pairwise significantly correlated with each other for both T2DM and obese groups, while RNFL nasal superior is not significantly correlated with any of these three $\mathrm{CN}$ parameters. Moreover, in general, the set of measurements of corneal nerve fiber are not correlated with the set of measurements of retinal nerve fiber with statistical significance at the level of $p<0.05$. Although not a universal rule, the implication is that the progression from pre-diabetic (obese) to T2DM might tend to entail a loss or diminishment on vertical lines indicate mean value, open squares indicate \pm standard deviation, and solid bars indicate minimum and maximum values. The raw data from the present work are shown scattered horizontally for clarity. T2DM, $N=44$; obese, $N=39$; [9], $N=617$; [10], $N=398$; [11], $N=3224$

of certain corneal nerve fibers or retinal nerve fibers, but not necessarily a loss of both corneal and retinal nerve fibers at the same time.

This work identifies four nerve cell properties where the differences in mean values are statistically significant between T2DM and obese participants. Although these trends hold for comparisons of mean values between the groups, there is a high degree of overlap in the distribution of individual measurements between the groups, as illustrated in Figs. 5 and 6. Thus, the measured values of nerve cell properties do not by themselves distinguish between the two groups, in contrast with $\mathrm{HbA} 1 \mathrm{c}$ and glucose (Figs. 1 and 2) that show a distinction between T2DM and obese. The practical significance is that each patient must be examined as a unique individual. Both IVCCM and OCT are useful for identifying nerve cell changes of interest and would need to be used over time to measure progression for a given individual.

Although glycemic control has been seen to improve some nerve parameters [22], loss of nerve fibers can lead to various ophthalmic dysfunctionalities, e.g., sensitivity impairment, and corneal erosion [29-31]. Therefore, it is important to monitor both the cornea and retina, with IVCCM and OCT, respectively, for remission or progressive damage to the eye in obese individuals and those with diabetes.

Supplementary Information The online version contains supplementary material available at https://doi.org/10.1007/s00417-021-05251-8. 
Funding Open access funding provided by University of Pécs. This work was supported in part by PTE ÁOK-KA No: 2020/02 and GINOP-2.1.1-15-2015-00609.

Data availability The [Supplementary_Table_S1] data used to support the findings of this study are included within the supplementary information file.

Code availability Not applicable.

\section{Declarations}

Ethics approval Ethical permission was granted by the University of Debrecen Ethics Committee (No. OGYÉI/2829/2017) and all participants provided written informed consent in accordance with the Helsinki Declaration.

Consent to participate Informed consent was obtained from all individual participants included in the study.

Consent for publication Patients signed informed consent regarding publishing their data and photographs.

Conflict of interest The authors declare no competing interests.

Financial disclosures Noémi Tóth none; David M. Silver none; Szabolcs Balla, none; Miklós Káplár, none; Adrienne Csutak MD, $\mathrm{PhD}$, none.

Open Access This article is licensed under a Creative Commons Attribution 4.0 International License, which permits use, sharing, adaptation, distribution and reproduction in any medium or format, as long as you give appropriate credit to the original author(s) and the source, provide a link to the Creative Commons licence, and indicate if changes were made. The images or other third party material in this article are included in the article's Creative Commons licence, unless indicated otherwise in a credit line to the material. If material is not included in the article's Creative Commons licence and your intended use is not permitted by statutory regulation or exceeds the permitted use, you will need to obtain permission directly from the copyright holder. To view a copy of this licence, visit http://creativecommons.org/licenses/by/4.0/.

\section{References}

1. Cade WT (2008) Diabetes-related microvascular and macrovascular diseases in the physical therapy setting. Phys Ther 88:13221335. https://doi.org/10.2522/ptj.20080008

2. Tavakoli M, Kallinikos PA, Efron N, Boulton AJM, Malik RA (2007) Corneal sensitivity is reduced and relates to the severity of neuropathy in patients with diabetes. Diabetes Care 30:18951897. https://doi.org/10.2337/dc07-0175

3. Misra SL, Braatvedt GD, Patel DV (2016) Impact of diabetes mellitus on the ocular surface: a review. Clin Exp Ophthalmol 44:278-288. https://doi.org/10.1111/ceo.12690

4. Tavakoli M, Petropoulos IN, Malik RA (2012) Assessing corneal nerve structure and function in diabetic neuropathy. Clin Exp Optom 95:338-347. https://doi.org/10.1111/j.1444-0938.2012. 00743.x

5. Tavakoli M, Ferdousi M, Petropoulos IN, Morris J, Pritchard N, Zhivov A, Ziegler D, Pacaud D, Romanchuk K, Perkins BA,
Lovblom LE, Bril V, Robinson Singleton J, Smith G, Boulton AJM, Efron N, Malik RA (2015) Normative values for corneal nerve morphology assessed using corneal confocal microscopy: a multinational normative data set. Diabetes Care 38:838-843. https://doi.org/10.2337/dc14-2311

6. dell'Omo R, Cifariello F, De Turris S, Romano V, Di Renzo F, Di Taranto D, Coclite G, Agnifili L, Mastropasqua L, Costagliola C (2018) Confocal microscopy of corneal nerve plexus as an early marker of eye involvement in patients with type 2 diabetes. Diabetes Res Clin Pract 142:393-400. https://doi.org/10.1016/j.diabr es.2018.06.010

7. Danilova I, Medvedeva S, Shmakova S, Chereshneva M, Sarapultsev A, Sarapultsev P (2018) Pathological changes in the cellular structures of retina and choroidea in the early stages of alloxan-induced diabetes. World J Diabetes 9:239-251. https:// doi.org/10.4239/wjd.v9.i12.239

8. Motamedi S, Gawlik K, Ayadi N, Zimmermann HG, Asseyer S, Bereuter C, Mikolajczak J, Paul F, Kadas EM, Brandt AU (2019) Normative data and minimally detectable change for inner retinal layer thicknesses using a semi-automated OCT image segmentation pipeline. Front Neurol 10. https://doi.org/ 10.3389/fneur.2019.01117

9. Hwang YH, Song M, Kim YY, Yeom DJ, Lee JH (2014) Interocular symmetry of retinal nerve fibre layer thickness in healthy eyes: a spectral-domain optical coherence tomographic study. Clin Exp Optom 97:550-554. https://doi.org/10.1111/cxo.12218

10. Rougier MB, Korobelnik JF, Malet F, Schweitzer C, Delyfer MN, Dartigues JF, Delcourt C, Helmer C (2015) Retinal nerve fibre layer thickness measured with SD-OCT in a populationbased study of French elderly subjects: the Alienor study. Acta Ophthalmol 93:539-545. https://doi.org/10.1111/aos.12658

11. Lamparter J, Schmidtmann I, Schuster AK, Siouli A, Wasielica-Poslednik J, Mirshahi A, Höhn R, Unterrainer J, Wild PS, Binder H, Lackner K, Beutel ME, Münzel T, Pfeiffer N, Hoffmann EM (2018) Association of ocular, cardiovascular, morphometric and lifestyle parameters with retinal nerve fibre layer thickness. PLoS One 13. https://doi.org/10.1371/journal.pone. 0197682

12. Brines M, Culver DA, Ferdousi M, Tannemaat MR, Van Velzen M, Dahan A, Malik RA (2018) Corneal nerve fiber size adds utility to the diagnosis and assessment of therapeutic response in patients with small fiber neuropathy. Sci Rep 8. https://doi.org/ 10.1038/s41598-018-23107-w

13. Lagali NS, Allgeier S, Guimarães P, Badian RA, Ruggeri A, Köhler B, Utheim TP, Peebo B, Peterson M, Dahlin LB, Rolandsson O (2017) Reduced corneal nerve fiber density in type 2 diabetes by wide-area mosaic analysis. Investig Ophthalmol Vis Sci 58:6318-6327. https://doi.org/10.1167/iovs.17-22257

14. Ziegler D, Papanas N, Zhivov A, Allgeier S, Winter K, Ziegler I, Brüggemann J, Strom A, Peschel S, Köhler B, Stachs O, Guthoff RF, Roden M, German Diabetes Study (GDS) Group for the GDS (GDS) (2014) Early detection of nerve fiber loss by corneal confocal microscopy and skin biopsy in recently diagnosed type 2 diabetes. Diabetes 63:2454-2463. https://doi.org/10.2337/db13-1819

15. Qu JH, Li L, Tian L, Zhang XY, Thomas R, Sun XG (2018) Epithelial changes with corneal punctate epitheliopathy in type 2 diabetes mellitus and their correlation with time to healing. BMC Ophthalmol 18. https://doi.org/10.1186/s12886-017-0645-6

16. Vagenas D, Pritchard N, Edwards K et al (2012) Optimal image sample size for corneal nerve morphometry. Optom Vis Sci 89:812-817. https://doi.org/10.1097/OPX.0b013e31824ee8c9

17. Dabbah MA, Graham J, Petropoulos IN, Tavakoli M, Malik RA (2011) Automatic analysis of diabetic peripheral neuropathy using multi-scale quantitative morphology of nerve fibres in corneal confocal microscopy imaging. Med Image Anal 15:738-747. https://doi.org/10.1016/j.media.2011.05.016 
18. Grubbs FE (1969) Procedures for detecting outlying observations in samples. Technometrics 11:1-21. https://doi.org/10.1080/ 00401706.1969.10490657

19. Bland JM (2000) The normal distribution. In: An introduction to medical statistics, 3rd edn. Oxford, pp 103-121

20. Kleinbaum DG, Kupper LL, Nizam A, Muller KE (2008) Oneway analysis of variance. In: Applied regression analysis and other multivariable methods, 4 th edn. Belmont, pp 420-480

21. Kahn SE, Hull RL, Utzschneider KM (2006) Mechanisms linking obesity to insulin resistance and type 2 diabetes. Nature 444:840846. https://doi.org/10.1038/nature05482

22. Jia X, Wang X, Wang X, Pan Q, Xian T, Yu X (2018) Guo L (2018) in vivo corneal confocal microscopy detects improvement of corneal nerve parameters following glycemic control in patients with type 2 diabetes. J Diabetes Res. https://doi.org/10.1155/2018/ 8516276

23. Davidson EP, Coppey LJ, Kardon RH, Yorek MA (2014) Differences and similarities in development of corneal nerve damage and peripheral neuropathy and in diet- induced obesity and type 2 diabetic rats. Investig Ophthalmol Vis Sci 55:1222-1230. https:// doi.org/10.1167/iovs.13-13794

24. Jia X, Zhong Z, Bao T et al (2020) Evaluation of early retinal nerve injury in type 2 diabetes patients without diabetic retinopathy. Front Endocrinol (Lausanne) 11:475672. https://doi.org/10. 3389/fendo.2020.475672

25. De Clerck EEB, Schouten JSAG, Berendschot TTJM et al (2017) Loss of temporal peripapillary retinal nerve fibers in prediabetes or type 2 diabetes without diabetic retinopathy: the Maastricht study. Investig Ophthalmol Vis Sci 58:1017-1027. https://doi.org/ 10.1167/iovs.16-19638
26. Pekel E, Tufaner G, Kaya H, et al (2017) Assessment of optic disc and ganglion cell layer in diabetes mellitus type 2. Med (United States) 96. https://doi.org/10.1097/MD.0000000000007556

27. Fawzy Khalil H, El-Mongy El-Saied Ali A, Mohamed Aly Ibrahim M, Fathi Mohammed Hatata A (2019) Assessment of retinal nerve fiber layer thickness using optical coherence tomography in patients with type 2 diabetes mellitus. https://doi.org/10.21608/ EJHM.2019.44826

28. Garcia-Martin E, Cipres M, Melchor I et al (2019) Neurodegeneration in patients with type 2 diabetes mellitus without diabetic retinopathy. J Ophthalmol 2019. https://doi.org/10.1155/2019/ 1825819

29. Eguchi H, Hiura A, Nakagawa H, Kusaka S, Shimomura Y, Pierscionek BK (2017) Corneal nerve fiber structure, its role in corneal function, and its changes in corneal diseases. https://doi. org/10.1155/2017/3242649

30. Kokot J, Wylęgała A, Wowra B, Wójcik Ł, Dobrowolski D, Wylęgała E (2018) Corneal confocal sub-basal nerve plexus evaluation: a review. Acta Ophthalmol 96:232-242. https://doi.org/10. 1111/aos.13518

31. Hoffmann EM, Schmidtmann I, Siouli A, Schuster AK, Beutel ME, Pfeiffer N, Lamparter J (2018) The distribution of retinal nerve fiber layer thickness and associations with age, refraction, and axial length: the Gutenberg health study. Graefes Arch Clin Exp Ophthalmol 256:1685-1693. https://doi.org/10.1007/ s00417-018-3991-z

Publisher's note Springer Nature remains neutral with regard to jurisdictional claims in published maps and institutional affiliations. 